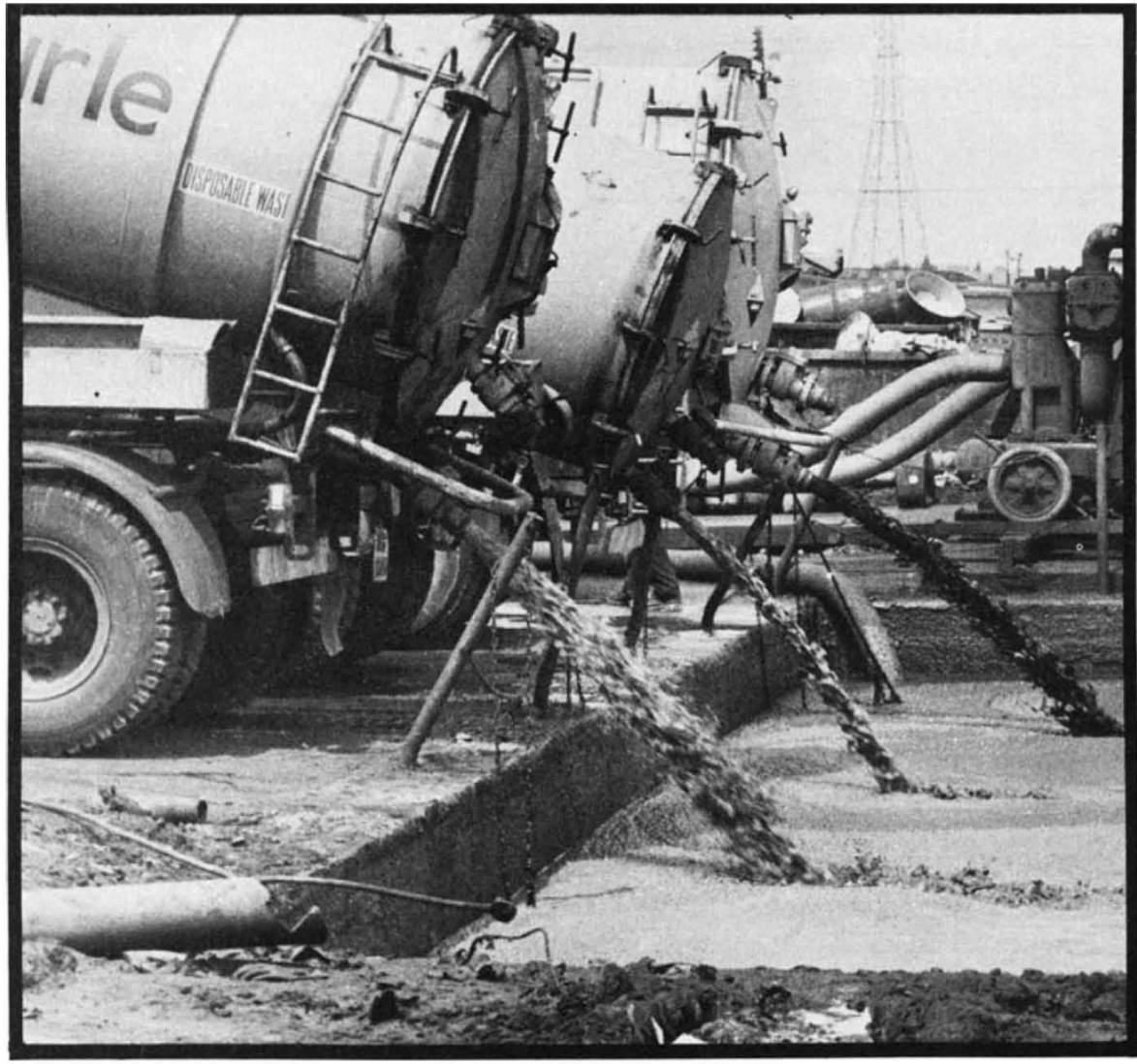

\section{Poisons, and how to dump them}

The growth of concern about the tipping of noxious and toxic wastes in the UK has taken place against a background of increasingly tough legislation, the programme for which has nonetheless now come to a temporary halt as the result of a tight economic situation. John Newell reports.

DURING the next few months, the first reponts are expected to emerge from technical groups within the Department of the Environment's waste disposal section. These groups are looking into the best ways of disposing of specific toxic wastes, including arsenic compounds, acids, mercury and other heavy metals in various concentrations, tarry residues and metal-finishing wastes.

Recommendations will take into account the 1974 Control of Pollution Act, which allows stringent requirements to be laid down for the disposal of particularly hazardous wastes. As soon as the Act comes into effect, all private operators will have to apply for licences for sites used to dump all noxious wastes. The power to withhold or remove licences, and the power to prescribe special codes of practice for especially toxic wastes provides local authorities with two powerful new safeguards. Nor do they any longer have the burden of proof of damage to the environment, as was the case under the 1972 Disposal of Toxic Wastes Act.

The 1974 Control of Pollution Act, the implementation of parts of which has been delayed for at least a year, goes further than the 1972 act in making it a duty for each local authority to make a survey of all industrial and domestic wastes created in its area. Local authorities must make detailed plans for the disposal of all wastes, and are compelled to introduce a licensing system for both landfill disposal sites and waste disposal operators. Local authorities will also be required to set out and maintain equivalent conditions for their own refuse disposal operations.

Although industry has welcomed the new act in principle, and has also supported the development of chemical treatment plants and modern incinerators, the economic situation has meant that the actual usage of such plants is somewhat disappointing, especoncerned. But the implementation of the 1974 act should help those companies by ensuring that adequate disposal facilities are provided by local cially where smaller companies are authorities.

For the foreseeable future, all existing means of disposal of toxic waste are bound to continue in use. The more recently designed chemical treatment plants for toxic wastes have, however, been designed with a view to increasing substantially the small proportion of their input which is at present recycled. Re-Chem International (which build chemical treatment plant) estimates that about $1 \mathrm{mil}$ lion tons of hazardous waste are produced annually in the UK, and this is thought to be increasing by about $1 \%$ (10,000 tons) a year.

The present need to restrict local authority expenditure is inevitably delaying the timetable for bringing the act into full operation. Nonetheless, the parts of the act requiring local authorities to survey all waste, products and those concerned with the introduction of increased penalties for existing pollution offences, are being introduced over the next few months, as they require little or no extra manpower.

On the other hand, the requirement to produce a formal waste disposal plan has been deferred for a year, after discussion with local authority associations, and so also has the requirement to introduce the licensing system. The parts of the act relating to water pollution will also be implemented in phases starting next year.

The fact that the act is now on the Statute Book is, however, already causing alterations in waste disposal practice in preparation for what is to come. Landfill will remain the principle means of disposal and the Department of the Environment has had a research programme on landfill with toxic waste running since 1973. One aim is to produce a code of practice for use by waste disposal authorities in the selection and control of disposal sites. The code will be concerned with water pollution and atmospheric pollution hazards, odour nuisance, and contamination of soils and vegetation. The team involved is developing a mathematical model of the behaviour of hazardous materials in the interiors of landfill tips.

Sheer shortage of tipping space is already encouraging the recycling and reclamation of ordinary household rubbish and this will probably soon be the case for actively toxic wastes, too. The Department of the Environment points out, justifiably, that the 1974 Control of Pollution Act has been the model for an EEC policy directive and that UK legislation in this field is ahead of most of the world. But the pressure in the future seems bound to be directed towards more incineration, more chemical treatment to render harmless, and more active recycling of toxic wastes. 